\title{
ABORDAGEM DO TEMA DOENÇAS SEXUALMENTE TRANSMISSÍVEIS, NO ENSINO FUNDAMENTAL REGULAR, A PARTIR DE UM JOGO DIDÁTICO
}

\author{
Jean Carlos MIRANDA*, Glaucia Ribeiro GONZAGA \&Patrícia Elias PEREIRA
}

Universidade Federal Fluminense, Instituto do Noroeste Fluminense de Educação Superior, Santo Antônio de Pádua, Rio de Janeiro, Brasil.

*Autor para correspondência: jeanmiranda@id.uff.br

DOI: http://dx.doi.org/10.18571/acbm.159

\section{RESUMO}

Independentemente do nível de ensino dos alunos da educação básica, tratar de temas como doenças sexualmente transmissíveis (DST) não é um processo simples. O Ensino Fundamental Regular apresenta o complicador do baixo desenvolvimento psicossocial para lidar com temas, que para os alunos é constrangedor. Utilizando o lúdico para modificar a forma de abordagem desse tema, é possível alcançar objetivos didáticos e a construção de conhecimento de forma dinâmica e sólida. Com essa premissa, este trabalho apresenta o jogo didático "Boliche das DST's - uma análise de caso", que possui uma abordagem diferente dos jogos didáticos tradicionais. Por não representar os clássicos jogos de cartas e tabuleiro, este jogo, que utiliza o método de Aprendizagem Baseada em Problema (ABP), se mostrou uma novidade para os alunos, que precisavam se organizar para trabalhar em equipe de forma diferente da qual estavam acostumados. Os resultados da avaliação do jogo didático validação, quanto a usabilidade, indicam que a proposta do jogo didático é válida para seu uso com alunos do Ensino Fundamental Regular.

Palavras-chave: Atividade Lúdica, Jogo Didático, PIBID, Doenças Sexualmente Transmissíveis.

\begin{abstract}
Independently of the level of education of students in basic education, dealing with issues such as sexually transmitted diseases (STD) is not a simple process. The Regular Fundamental Education presents the complicator of the low psychosocial development to deal with themes, which for the students is embarrassing. Using the ludic to modify the way of approaching this theme, it's possible to achieve didactic objectives and the construction of knowledge in a dynamic and solid way. With this premise, this work presents the didactic game "DST's Bowling - a case study", which has a different approach to traditional didactic games. Because it does not represent the classic board and card games, this game, which uses the Problem Based Learning method (PBL), was a novelty for the students, who needed to organize themselves to work in teams in a different way than they were accustomed. The results of the evaluation of the didactic game validation, as usability, indicate that the proposal of the didactic game is valid for use with students of Regular Fundamental Education.
\end{abstract}

Keywords: Ludic activity, Didactic game, PIBID, Sexually Transmitted Diseases.

\section{Introdução}

A adolescência é um período de grandes modificações físicas, psicológicas e emocionais. Seus limites cronológicos variam de 10 a 19 anos, segundo a Organização Mundial da Saúde, e de 15 a 24 anos, segundo a Organização das Nações Unidas (EISENSTEIN, 2005). Constitui-se em uma fase marcada pela vulnerabilidade (BESERRA et al., 2008) decorrente da ausência de maturidade e inabilidade para lidar com as situações que se apresentam, sendo comuns os conflitos 
entre os adolescentes e seus pais, professores e demais responsáveis por sua educação (MIRANDA, 2013).

A instabilidade emocional, a falta de conhecimento, a necessidade de autoafirmação, o início precoce da vida sexual, dentre outros fatores, coloca os adolescentes em situações de risco, como por exemplo, relações sexuais sem planejamento, sem a utilização de preservativos. Nesse cenário, ganha destaque o aumento da incidência de doenças sexualmente transmissíveis (DST's) (MIRANDA, 2013), consideradas um grave problema de saúde pública (DÜSMAN et al., 2009). “As DST's são as principais causas de morbidez entre os adolescentes sexualmente ativos e 70\% dos casos dessas doenças acontecem na faixa de 15 a 24 anos de idade" (MANHÃES et al., 2006; p. 12527).

A escola, portanto, desempenha importante papel como espaço de análise e discussão do tema, uma vez que, por meio da transmissão de informações de forma direcionada (BESERRA et al., 2008), com a aplicação de atividades didáticas intencionais (MANHÃES et al., 2006), pode capacitar os adolescentes à percepção de situações/fatores de risco (BESERRA et al., 2008). Nesse sentido, é necessária a abordagem do tema com utilização de modalidades didáticas diferenciadas que motivem e envolvam os adolescentes, enriquecendo o conteúdo e estimulando a reflexão-ação. "Uma vez que os alunos encontram-se motivados, participam das aulas, trazem curiosidades, levantam questões, tem vontade de aprenderem mais chances de se envolverem profundamente com a situação de aprendizagem (ROSA; LANDIM, 2014; p. 135)."

Nesse sentido, os jogos didáticos são importantes recursos, uma vez que têm valor formativo que pressupõe relação social de interação (ELEUTÉRIO et al., 2010), estimulam o interesse do aluno e levam o professor à condição de mediador da aprendizagem (CUNHA e ZIMMER, 2016).

O jogo didático oferece o estímulo e o ambiente propícios que favorecem o desenvolvimento espontâneo e criativo dos alunos e permite ao professor ampliar seu conhecimento de técnicas ativas de ensino, desenvolver capacidades pessoais e profissionais para estimular nos alunos a capacidade de comunicação e expressão, mostrando-lhes uma nova maneira, lúdica, prazerosa e participativa de relacionar-se com o conteúdo escolar, levando a uma maior apropriação dos conhecimentos envolvidos (BRASIL, 2006, p. 28).

Jogos didáticos têm sido utilizados como estratégia para educação em saúde (YONEKURA e SOARES, 2010), sobretudo na abordagem de temas relacionados à educação sexual dos adolescentes (e.g. COSTA; GONZAGA; MIRANDA, 2016; MIRANDA et al., 2016a). Tais temas são, frequentemente, difíceis de abordar, principalmente em salas de aula com alunos do Ensino Fundamental, devido aos tabus e preconceitos que os permeiam. Soma-se a isso o grande número de dúvidas e questionamentos que os adolescentes e jovens apresentam.

Dado o aumento no número de casos de DST's observado a cada ano, entre adolescentes, decorrente da falta de informações e consciência da gravidade da questão (SANTANA et al., 2017), e a necessidade de colaborar com a abordagem dessa problemática e tornar as discussões mais didáticas, melhorando o processo de construção do conhecimento, foi desenvolvido o jogo didático "Boliche das DST's - uma análise de casos".

O presente trabalho objetiva apresentar e avaliar o jogo didático "Boliche das DST's - uma análise de casos", desenvolvido no âmbito do Subprojeto "PIBID Ciências Naturais - Pádua", como ferramenta na abordagem do tema doenças sexualmente transmissíveis com alunos do Ensino Fundamental Regular. 


\section{Biomedica Brasiliensia}

\section{Metodologia}

A proposta principal do jogo didático desenvolvido é a abordagem de questões relacionadas às DST's, seus sintomas, formas de contágio, tratamento e profilaxia, não como um jogo tradicional de um tabuleiro com percursos definidos, ou com cartas em um baralho, mas baseado no método de estudo de casos. Esse método, com origem na Medicina, mas aplicado em pesquisas qualitativas de várias áreas do conhecimento, consiste em uma análise aprofundada, direcionada e pontual de um indivíduo, uma situação ou um grupo de pessoas, e sua consequente discussão, podendo ser exploratória, descritiva ou explanatória (YIN, 2010). A classificação do jogo didático neste método é a de Aprendizagem Baseada em Problemas (Método ABP), na qual o professor atua como orientador-mediador (SALES e ANDRADE, 2017), e faz com que os alunos construam o conhecimento científico através de discussões com seus pares, na tentativa de solucionar os casos propostos (BERBEL, 1998).

\subsection{O jogo didático}

Um kit completo do jogo possui 10 pinos plásticos de boliche, de $20 \mathrm{~cm}$ de altura e numerados de 1 a 10, 10 cartas-caso (fichas) de $15 \times 10 \mathrm{~cm}$ (uma para cada pino de boliche) (APÊNDICE A), uma bola plástica de $15 \mathrm{~cm}$ de diâmetro, 01 cronômetro digital e 01 dado de seis faces. O jogo também possui uma ficha de respostas (APÊNDICE B) e um manual de regras (APÊNDICE C), em tamanho A4 padrão, para consulta pelo mediador da atividade, neste caso, o professor regente da turma.

Cada uma das cartas-caso possui um caso clínico específico e detalhado para que cada equipe identifique o caso tratado, apresente o diagnóstico a partir do quadro sintomático apresentado, e forneça as recomendações de tratamento e profilaxia para o paciente da carta-caso obtida. Para a composição do conteúdo das cartas-caso foi realizada uma revisão bibliográfica e eleitas dez DST's para abordagem no jogo didático: Sífilis, Tricomoníase, Gonorreia, Condiloma Acuminado (HPV), AIDS, Herpes Genital, Cancro Mole, Hepatite C, Donovanose e Doença Infamatória Pélvica (DIP).

\subsection{As regras e a dinâmica do jogo}

O formato deste jogo foi escolhido para que o mesmo envolvesse todos os alunos de uma turma, de forma a desenvolver não apenas a construção do conhecimento, mas também as construções psicossociais, as relações inter e intrapessoais, que são tão importantes para a formação de um cidadão consciente e atuante em sua comunidade (JESUS et al., 2013), fatores cuja importância é destacada por Almeida (1974), para o uso de jogos didáticos, e por documentos que norteiam a educação básica, como os Parâmetros Curriculares Nacionais (BRASIL, 1998; 2002). A dinâmica da atividade consiste em dividir a turma em 4 a 6 grupos (podendo ter o máximo de 10 grupos), dependendo do tamanho da turma e a critério do professor) e selecionar um representante de cada grupo. O professor da turma, atuando como mediador, organizará a ordem de participação dos grupos através do lançamento do dado. O representante do primeiro grupo jogará a bola de boliche para derrubar um dos pinos presentes na pista, pegará o pino caído e levará o mesmo para o seu grupo. O segundo representante seguirá o mesmo procedimento até que cada grupo possua um pino. Quando cada grupo tiver o seu pino, o cronômetro é acionado. Os grupos terão 20 minutos para analisar o paciente apresentado na carta-caso, diagnosticá-lo, esclarecê-lo quanto ao seu quadro sintomático e fazer as devidas recomendações sobre tratamento e profilaxia, escrevendo todas as informações em uma folha de papel. Neste tempo, para que o mediador não se torne mero coadjuvante da atividade e possa auxiliar na construção do conhecimento, é de grande importância que percorra os grupos e os auxilie, esclarecendo pequenas dúvidas. Esse 
processo de análise dos grupos é mediado ininterruptamente pelo professor, devido a importância do direcionamento das construções científicas, da motivação para a construção efetiva do conhecimento e da mediação das relações sociais durante o desenvolvimento da atividade, para que as dificuldades em ambos os campos sejam superadas (MAHONEY e ALMEIDA, 2005; NEVES e CARVALHO, 2006).

Findado o tempo, o mediador interrompe as atividades dos grupos, e solicita aos representantes de cada grupo (mesma ordem do início da atividade) que apresentem seus pacientes, falem sobre seus diagnósticos e as recomendações indicadas pelo grupo. Durante essa apresentação deve haver interações dos demais grupos quanto ao diagnóstico dos pacientes, tornando a construção do conhecimento mais coletiva. A apresentação ocorre com a mediação do professor, uma vez que a aprendizagem pode ser influenciada positiva ou negativamente de acordo com as estratégias didáticas utilizadas pelo mesmo (COSTA, 2011; OLIVEIRA, 2016), e que a construção final deve ser orientada não apenas para a mediação do tempo da atividade, mas também para exposição correta das ideias de um grupo para os outros, já que não tiveram acesso aos outros casos disponibilizados no jogo.

\subsection{Local de aplicação}

A aplicação do jogo didático ocorreu em duas turmas do $8^{\circ}$ ano do Ensino Fundamental Regular, com a participação de 31 alunos da Escola Municipal "Escola Viva" Professora Edy Belloti, uma das principais escolas do município de Santo Antônio de Pádua/RJ. Sendo a maior da rede municipal de ensino da cidade, atende a aproximadamente, 1.200 alunos da Educação Infantil e do Ensino Fundamental Regular. Considerada uma escola-modelo, apresenta o maior IDEB (Índice de Desenvolvimento da Educação Básica) $(5,9)$ da rede pública municipal de Santo Antônio de Pádua (MIRANDA et al., 2016b).

A escolha da Escola Municipal "Escola Viva" Professora Edy Belloti para desenvolvimento e aplicação da atividade, justifica-se pelo fato de ser escola parceira do Subprojeto PIBID Ciências Naturais no município. Tal condição facilita o desenvolvimento de ações didáticas diferenciadas, como a proposta nesse trabalho.

\subsection{Ferramenta de avaliação}

A fim de avaliar algumas características do jogo desenvolvido foi construído um questionário básico de usabilidade utilizando alguns critérios estabelecidos por Nielsen e Loranger (2007). A avaliação através desse quesito se faz importante por considerar a opinião dos alunos no processo de produção do material didático. Essa prática auxilia na correção de possíveis erros de planejamento para que o material didático seja utilizado de forma eficiente no processo ensinoaprendizagem, na totalidade de sua capacidade educacional.

O questionário de avaliação, preenchido de forma anônima, se constitui de 06 questões fechadas e 01 questão aberta para coleta de sugestões e reclamações. Como o questionário foi aplicado a alunos do Ensino Fundamental Regular, as perguntas foram elaboradas de forma que sua resolução fosse simples e rápida. As questões fechadas foram: (i) As regras do jogo são claras? (ii) As perguntas são objetivas? (iii) $\mathrm{O}$ visual do jogo é agradável? (iv) $\mathrm{O}$ jogo estimula o aprendizado? (v) A aula ficou mais interessante com o jogo? (vi) O tempo de jogo é suficiente? Para todas as questões os alunos deveriam assinalar sim, não ou pode melhorar.

\section{Resultados e discussão}

Os dados apresentados na tabela 1 indicam boa aceitação do jogo didático "Boliche das DST - uma análise de caso" pelos alunos participantes da atividade de validação da usabilidade 
do jogo. Mesmo com uma porcentagem alta sobre a clareza das regras do jogo, o índice de objetividade não foi tão elevado. Atribuímos este baixo valor (se comparado aos demais) à modalidade utilizada para o jogo, que foi a análise de casos clínicos. A dinâmica diferenciada do jogo didático, sem questões a serem respondidas e um percurso com obstáculos a ser percorrido, como num jogo de tabuleiro tradicional, e sim um caso clínico de paciente fíctício, com informações a serem analisadas e discutidas, causou estranheza e os alunos tiveram certa dificuldade em entender seus objetivos.

Tabela 1: Percentuais de respostas "sim", obtidos através da aplicação do questionário.

\begin{tabular}{lc}
\multicolumn{1}{c}{ Questões } & Percentual de respostas "sim" \\
\hline As regras do jogo são claras? & 77,4 \\
As perguntas são objetivas? & 51,6 \\
O visual do jogo é agradável? & 74,2 \\
O jogo é estimulante? & 80,6 \\
O jogo deixou a aula mais interessante? & 77,4 \\
O tempo do jogo foi insuficiente, e gostariam de jogar mais? & 83,9 \\
\hline
\end{tabular}

Outro ponto a ser destacado nos resultados obtidos é que a maioria dos alunos (conforme dados da tabela 1) achara insuficiente o tempo de 20 minutos para a resolução do caso obtido, alegando que gostariam de discutir com o grupo, por mais tempo, para melhor construção da conclusão do caso. Porém, é importante ponderar que a atividade não consiste apenas no recebimento de um caso para ser resolvido. Há toda uma dinâmica prévia de organização da turma, divisão das equipes, ordenação do jogo; bem como há toda a dinâmica posterior de apresentação do caso e das conclusões de cada equipe para um debate coletivo. Todo esse procedimento dentro de uma aula regular do ensino público não permite que o tempo seja prolongado para uma das etapas do jogo, pois é necessário que a dinâmica não seja interrompida para que o aprendizado seja efetivo.

Os autores deste relato acreditam que a proporção de tempo para a conclusão de cada etapa da atividade é suficiente para que não ocorra a dispersão da atenção dos alunos, e para que os alunos desenvolvam, em segundo plano, o raciocínio logico e rápido, a memória, a linguagem e outros aspectos cognitivos, que também são importantes no processo de ensino e que também faz parte do papel de ação docente e escolar.

Fazendo uma breve análise qualitativa, a aplicação de um jogo didático no qual os alunos precisem, em grupos, analisar um caso clínico e associa-lo ao conhecimento científico e popular (além do tácito), transforma o aluno de agente passivo a ativo e pensante no processo ensinoaprendizagem. Além disso, há o aumento da capacidade de relações interpessoais, uma vez que a construção e resolução da atividade é feita através de discussões internas em cada grupo, e depois com o coletivo dos alunos. Os benefícios de proporcionar essa interação social em sala de aula, com um objetivo comum, resultam no desenvolvimento de fatores biológicos, como a capacidade cognitiva (que envolve raciocínio, memória, linguagem, percepção, dentre outros) (MAHONEY e ALMEIDA, 2005).

Além disso, tem-se o fato da construção do conhecimento e todo o debate relacionado ser iniciado com o uso de um jogo didático. Sobre isso, Neves e Carvalho (2006) afirmam que emoções como curiosidade, divertimento, estados de aceitação, ambição (de solucionar o problema), são explicitamente favoráveis à aprendizagem. Para que a aprendizagem seja realmente significativa é necessário ser precedida de experiências afetivas (SANTOS, 2007) como as proporcionadas pelo uso de jogos didáticos em sala de aula, mediados pelo professor. Essa mediação é de extrema importância para o sucesso do processo de ensino (não apenas o conteudista, mas também o psicossocial) (OLIVEIRA, 2016), pois quando o educando participa ativamente do processo educacional de forma dinâmica e prazerosa, a aprendizagem é facilitada (NEVES e CARVALHO, 2006). 
A metodologia utilizada no jogo didático "Boliche das DST's - uma análise de casos" permite aos alunos a discussão científica direcionada sobre um assunto real que afeta a todos, sem distinção, permitindo além da construção do conhecimento científico, o esclarecimento de dúvidas e a quebra de alguns tabus sociais que ainda permeiam nossa sociedade.

\section{Considerações finais}

Este relato não teve como pretensão afirmar ou impor que jogos didáticos são a salvação do processo de ensino. Cada professor tem autonomia para escolher/produzir seu recurso didático de modo condizente com suas características pessoais, a estrutura da sua instituição de ensino, e as singularidades de seus alunos. O que defendemos aqui é a ideia de que jogos didáticos são importantes motivadores no processo ensino-aprendizagem e que podem interferir na formação do aluno de várias maneiras distintas.

Quando se fala em jogo didático, a primeira coisa que se pensa é em um conjunto de cartas, peões e um tabuleiro. A proposta desse jogo didático tem o diferencial de não possuir essa estrutura característica. A escolha de um estudo de casos clínicos fictícios de DST's reais faz com que os alunos debatam a temática de forma madura, com embasamento científico, buscando esclarecer o paciente apresentado no caso relatado. Esta dinâmica muda completamente o papel de sujeito passivo do aluno no processo ensino-aprendizagem, tornando-o ator principal na construção do conhecimento científico, de maneira sólida e duradoura.

O outro diferencial do jogo didático ora apresentado, é o tema escolhido, que ainda é abordado de forma superficial, devido a um antigo tabu social que é discutir sobre sexualidade e temas a ela relacionados. Essa discussão normalmente ocorre entre os próprios alunos, de forma "escondida" e, muitas vezes, permeada de equívocos. O resultado disso se reflete no pouco conhecimento dos jovens acerca dessa temática. Quando se inicia a abordagem em sala de aula (o que nem sempre é fácil no Ensino Fundamental Regular), a discussão sobre o tema resume-se em uma série questionamentos dos alunos, e não em uma construção coletiva e científica. Por isso, o jogo didático desenvolvido se destinou a trazer casos para que os alunos avaliem, usando seus conhecimentos (acadêmico/escolar, popular e tácito) para que, através de associações e construções, cheguem às conclusões concretas sobre o que estão analisando.

\section{Agradecimentos}

Os autores agradecem à CAPES pelo financiamento do Subprojeto PIBID "Ciências Naturais - Pádua".

\section{Referências}

BERBEL, N.A.N. A problematização e a aprendizagem baseada em problemas. Interface: Comunicação, Saúde e Educação, v. 2, n. 2, p. 139-154, 1998.

BESERRA, E.P.; PINHEIRO, P.N.C.; ALVES, M.D.S.; BARROSO, M.G.T. Adolescência e vulnerabilidade às doenças sexualmente transmissíveis: uma pesquisa documental. DST - Jornal Brasileiro de Doenças Sexualmente Transmissíveis, v. 20, n. 1, p. 32-35, 2008.

BRASIL. Ministério da Educação. Secretaria de Educação Fundamental. Parâmetros Curriculares Nacionais: Ciências Naturais. ( $3^{\circ}$ e $4^{\circ}$ ciclos do Ensino Fundamental). Brasília: MEC. 1998. 
BRASIL. Ministério da Educação. Secretaria de Educação Básica. Parâmetros Curriculares Nacionais: Ciências da natureza, Matemática e suas tecnologias. Brasília: MEC/SEB. 2002.

COSTA, R.C.; GONZAGA, G.R.; MIRANDA, J.C. Desenvolvimento e validação do jogo didático "Desafio Ciências - Animais" para utilização em aulas de ciências no Ensino Fundamental Regular. Revista da SBEnBIO, v. 9, p. 9-20, 2016.

COSTA, S.F.P. Dificuldades de Aprendizagem no Contexto Psicopedagógico. Profissão Docente, v. 20, n. 23, p. 154-157, 2011.

CUNHA, A. P. A.; ZIMMER, R. Jogos didáticos como recursos complementares para o ensinoaprendizagem de Química. Tempos e Espaços em Educação, v. 9, n. 19, p. 13-24, 2016.

DÜSMAN, E.; GOIS, K.S.; GOMES, E.M.V.; CAMARGO, T.; PENNA, L.M.C.; GUHUR, M.L.P. Conhecimentos e atitudes dos adolescentes da cidade de Maringá-PR a respeito de doenças sexualmente transmissíveis e métodos anticoncepcionais. SaBios - Revista de Saúde e Biologia, v. 4, n. 1, p. 12-20, 2009.

EISENSTEIN, E. Adolescência: definições, conceitos e critérios. Adolescência e Saúde, v. 2, n. 2, p. 6-7, 2005.

ELEUTÉRIO, L.F.; TOMAZ, E.D.; DINIZ, R.S.; ANDRADE, S.O. O uso de jogos nas aulas de matemática nas séries iniciais. In: Encontro Paraibano de Educação Matemática, 2010.

JESUS, I.S.; NOGUEIRA, F.B.; SILVA, E.E.; SANTOS, F.R. O Jogo "O elemento que liga" como recurso didático no ensino de ligações químicas. Scientia Plena, v. 9, n. 7, p. 1-6, 2013.

MAHONEY, A.A.; ALMEIDA, L.R. Afetividade e processo ensino-aprendizagem: contribuições de Henri Wallon. Psicologia da Educação, v. 20, p. 11-30, 2005.

MANHÃES. L.L.A.; MARINHO, R.S.S.; SILVA, L.G.M.; SANTOS, M.M.; BARRETO, C. M. B. Brincando que se aprende: Um jeito divertido de aprender sobre métodos anticoncepcionais. In: XII Congresso Nacional de Educação, p. 12517-12534, 2015.

MIRANDA, J.C. Adolescência e vida sexual: o retrato de uma escola pública da região metropolitana do Rio de Janeiro. SaBios - Revista de Saúde e Biologia, v. 8, n. 2, p.31-40, 2013.

MIRANDA, J.C.; GONZAGA, G.R.; OLIVEIRA, B.; BORGES, P. N.; LUCAS, Y. O. S. Avaliação do jogo didático "Em Busca da Fecundação" como ferramenta para abordagem de temas relativos à reprodução humana. Revista da SBEnBIO, v. 9, p. 1845-1856, $2016 \mathrm{a}$.

MIRANDA, J.C.; GONZAGA, G.R.; COSTA, R.C.; FREITAS, C.C.C.; CÔRTES, K.C. Jogos didáticos para o ensino de Astronomia no Ensino Fundamental. Scientia Plena, v. 12, n. 2, p. 1$11,2016 b$.

NEVES, M.C.; CARVALHO, C. A importância da afectividade na aprendizagem da matemática em contexto escolar: um estudo de caso com alunos do $8^{\circ}$ ano. Análise Psicológica, v. 24, n. 2, p. 201-215, 2006. 
NIELSEN, J.; LORANGER, H. Usabilidade na web: projetando websites com qualidade. Rio de Janeiro: Campus, 2007.

OLIVEIRA, D.C. Determinantes comportamentais e emocionais do processo ensinoaprendizagem. Caderno Intersaberes, v. 5, n. 6, p. 1-12, 2016.

ROSA, I.S.C.; LANDIM, M. F. Modalidades didáticas no ensino de biologia: uma contribuição para aprendizagem e motivação dos alunos. Tempos e Espaços em Educação, v. 7, n. 14, p. 133 $144,2014$.

SALES, L.M.M.; ANDRADE, L.S. A mediação de conflitos e o direito: desenvolvendo habilidades a essa nova realidade. Prim@ Facie-Direito, História e Política, v. 16, n. 33, p. 129, 2017.

SANTANA, A.R.; CRISOSTIMO, A.L.; MOSER, A.S.; PILATI, L.; PARTEKA, L.M. Doenças sexualmente transmissíveis e o jogo do tabuleiro. In: CRISOSTIMO, A.L.; KEIL, C.A. (Org.). O lúdico e o ensino de Ciências: saberes do cotidiano. Guarapuava: Editora da Unicentro. $1^{\circ} \mathrm{ed}$., p. 113-128, 2017.

SANTOS, F.M.T. As emoções nas interações e a aprendizagem significativa. Ensaio - Pesquisa em Educação em Ciências, v. 9, n. 2, p. 151-161, 2007.

YIN, R.K. Estudo de caso: planejamento e métodos. 4a .ed. Porto Alegre: Bookman, 2010.

YONEKURA, T.; SOARES, C.B. O jogo educativo como estratégia de sensibilização para coleta de dados com adolescentes. Revista Latino-Americana de Enfermagem, v. 18, n. 5, p. 968-974, 2010 . 


\section{APÊNDICE A}

\section{PST'S}

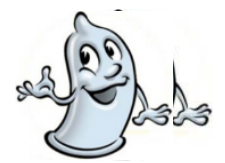

1) Cláudio tem 18 anos e procura um médico queixando-se de "problemas lá embaixo". Diz que não quer ser atendido por mulher, só quer uma pomada para machucado. Após insistência do médico, admite que tem úlceras genitais e ínguas na região da virilha. Um exame clínico rápido revelou gânglios aumentados. Cláudio afirma usar camisinha às vezes, quando sai com pessoas que não "são de confiança".

\section{QDST'S}

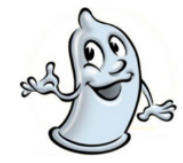

2) Maria leva sua filha Marcela, de 12 anos a uma consulta com o ginecologista por que a menina está com corrimento amarelo-esverdeado e de cheiro forte, sua vulva está irritada e apresenta coceira. Ela também sente dor e ardência ao urinar. Marcela afirma nunca ter mantido relações sexuais. 


\section{APÊNDICE A}

\section{QDST'S}

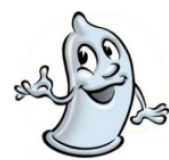

3) Com uma vida sexual bem ativa Raimundo gostava de uma boa balada e sempre com uma menina diferente. Porém, o destino lhe pregou uma peça e ele se apaixonou por Laura e depois de algum tempo de namoro eles se casaram. Raimundo nunca se importou em ir ao médico sua saúde; minha saúde é de ferro, diz ele. Mais de um tempo para cá vem sentindo dores em seus testículos e quando vai urinar tem uma sensação de ardor e esquentamento ao urinar. Laura, sabendo disso e preocupada com sua saúde, vai à uma consulta com sua médica (algo que ela faz cada seis meses). Como Laura notou um aumento no corrimento e têm ocorrido sangramentos fora da época de menstruação, resolveu antecipar sua consulta. Após a consulta, realizou alguns exames médicos, cujos resultados indicaram que ela está grávida e apresenta um quadro de enfermidade que, se não for tratada corretamente, poderá causar no bebê a chamada oftalmia neonatal.

\section{ODST'S}

4) Durante um contato mais íntimo com sua namorada, Antônio percebe uma verruga em sua namorada e logo a questiona sobre o que seria e se ela sente dor. Lavínia responde que não sabe o que é, pois não tinha notado essas verrugas e que não esta sentindo dor. Preocupado, Antônio marca uma consulta médica para Lavínia e a acompanha. Chegando lá, o médico examina a área onde está a verruga e identifica outras. Ele realiza o exame preventivo em Lavínia e encaminha Antônio para uma consulta com seu urologista. 


\section{APÊNDICE A}

\section{ODST'S}

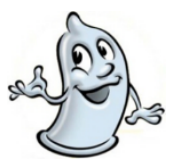

5) Homem de 32 anos, bissexual, usuário de cocaína e com vida noturna intensa (é músico). Há cerca de três anos procurou ajuda médica em função de febres diárias vespertinas e foi diagnosticado com pneumonia. Nos últimos 12 meses, apresentou febre mais intensas $\left(41^{\circ} \mathrm{C}\right)$, candidíase bucal e diarreias ocasionais. Teve grande perda de peso (de $76 \mathrm{Kg}$ para pouco mais de $40 \mathrm{Kg}$ ) e sua pela tem aspecto enegrecido.

\section{QDST'S}

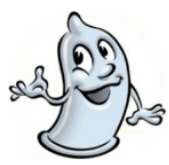

6) Rejane, de 35 anos, procura o ginecologista e relata dor e ardência vaginal, principalmente após as relações sexuais. Ela queixa-se também de febrícula (febre passageira). Após exame clínico, o médico identifica lesões genitais (pequenas bolhas), das quais saem secreção quando estouradas. Rejane é promíscua e raramente faz uso de preservativos. 


\section{APÊNDICE A}

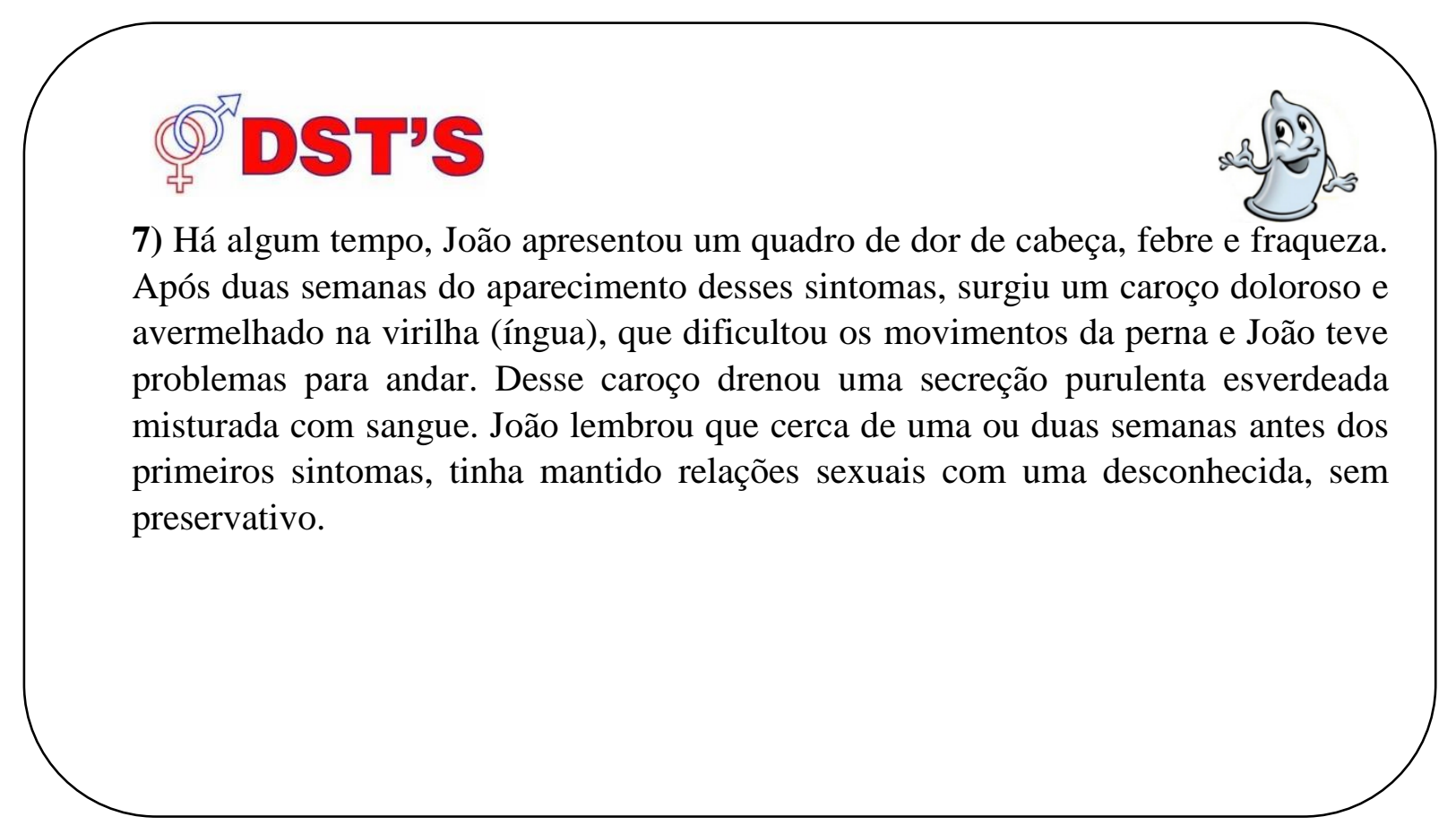

\section{QTDST'S}

8) Sebastião é usuário de drogas e junto com seu grupo de "amizades" compartilham seringas para injetarem cocaína nas veias. Há algum tempo, apresenta sintomas que têm tirado seu sono. Com frequência, apresenta dores no estômago e náuseas. Mais recentemente, seus olhos adquiriram um aspecto amarelado, suas fezes estão esbranquiçadas e sua urina escura da cor de Coca-Cola. Ele lembra ter acordado nu, a lado de uma amiga (que tem olhos amarelados) após uma de suas "viagens" pelo uso de drogas. Tem certeza que não usou camisinha. 


\section{APÊNDICE A}

\section{QDST'S}

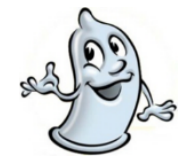

9) Paulo, ao tomar banho, notou que havia feridas e caroços avermelhados em sua região genital. Ele achou estranho que, ao tocá-los, houve sangramento, mas o que o intrigou foi o fato de que ele não sentiu dor. Paulo não procurou atendimento médico. Como as feridas e caroços não doíam, ele achou que não era nada grave e, por isso, não procurou atendimento médico. Com o passar do tempo, as feridas ficaram maiores e, como estavam abertas, facilitaram a infecção por bactérias. Com medo, Paulo resolveu procurar atendimento médico. Ele afirma transar sem camisinha com frequência e admite não ter hábitos de higiene adequados.

\section{(4) DST'S}

10) Núbia começou a namorar "firme" e resolveu que precisava de uill llı́tudo contraceptivo, já que seu parceiro não gosta de usar camisinha e ela não tem a intenção engravidar nesse momento. Depois de pesquisar, achou que o melhor método seria a colocação de um DIU, mas durante o procedimento de inserção do dispositivo houve uma contaminação por bactérias. Algum tempo depois, Núbia começou a sentir dores na parte baixa do abdome, febre, dores nas costas e a vomitar. Também começou a sentir dores durante a relação sexual. Resolveu voltar ao consultório médico para saber o que tinha dado errado no procedimento. 


\section{APÊNDICE A}

\section{VERSO DAS FICHAS}

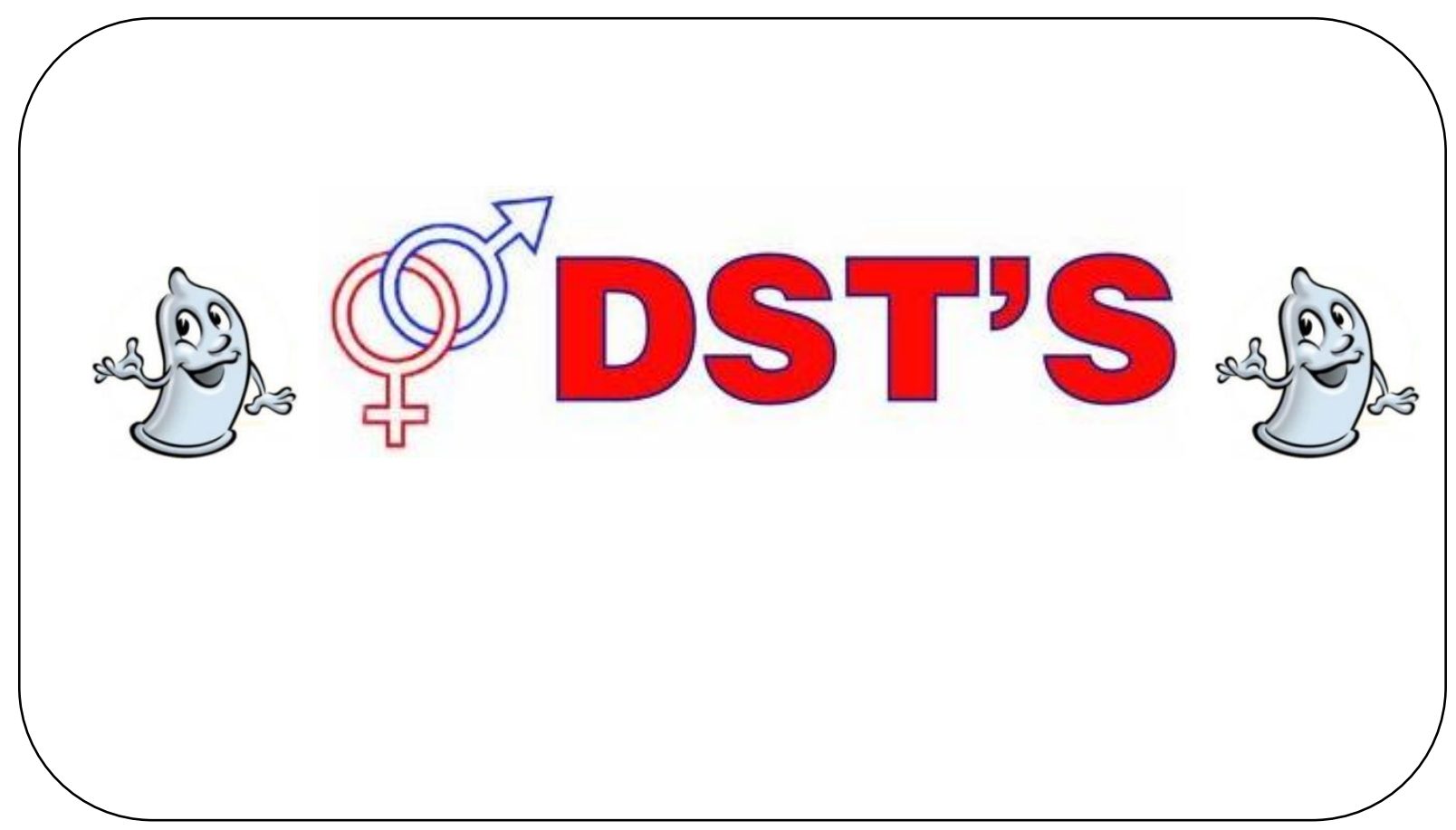


APÊNDICE B
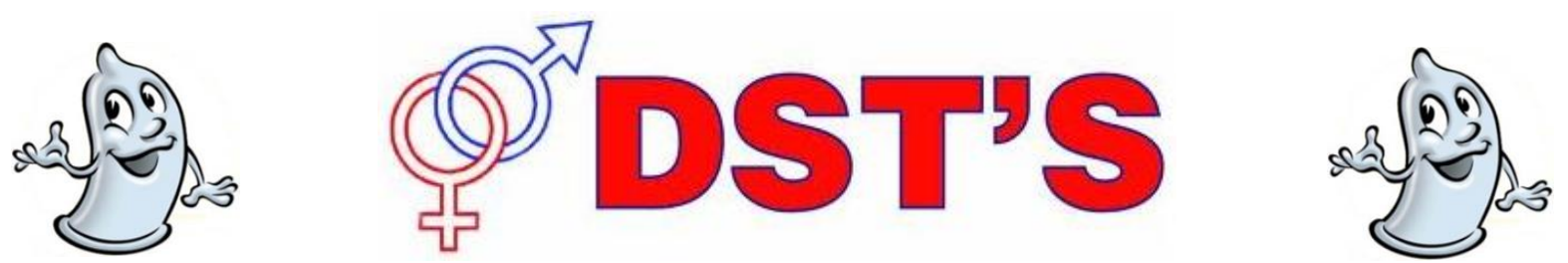

RESPOSTA DAS FICHAS

\begin{tabular}{|c|c|}
\hline FICHA & DOENÇAS \\
\hline 1 & SÍFILIS \\
\hline 2 & TRICOMONÍASE \\
\hline 3 & GONORREIA \\
\hline 4 & CONDILOMA ACUMINADO (HPV) \\
\hline 5 & AIDS \\
\hline 6 & HERPES GENITAL \\
\hline 7 & CANCRO MOLE \\
\hline 8 & HEPATITE C \\
\hline 9 & DONOVANOSE \\
\hline 10 & DOENÇA INFAMATÓRIA PÉLVICA (DIP) \\
\hline
\end{tabular}




\section{APÊNDICE C}

\section{EQUIPE}

JEAN CARLOS MIRANDA (COORDENAÇÃO) GLAUCIA RIBEIRO GONZAGA (COLABORAÇÃO)

Bolsista

PATRÍCIA ELIAS PEREIRA

Financiamento: PIBID/CAPES

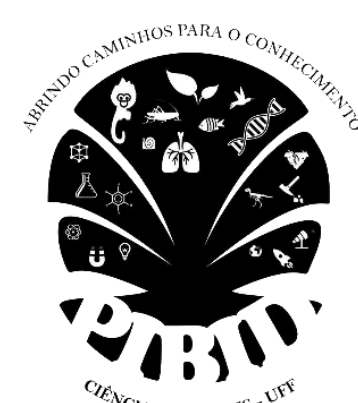

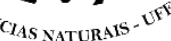

\section{MANUAL DE REGRAS}

JOGO DIDÁTICO BOLICHE DAS DST's

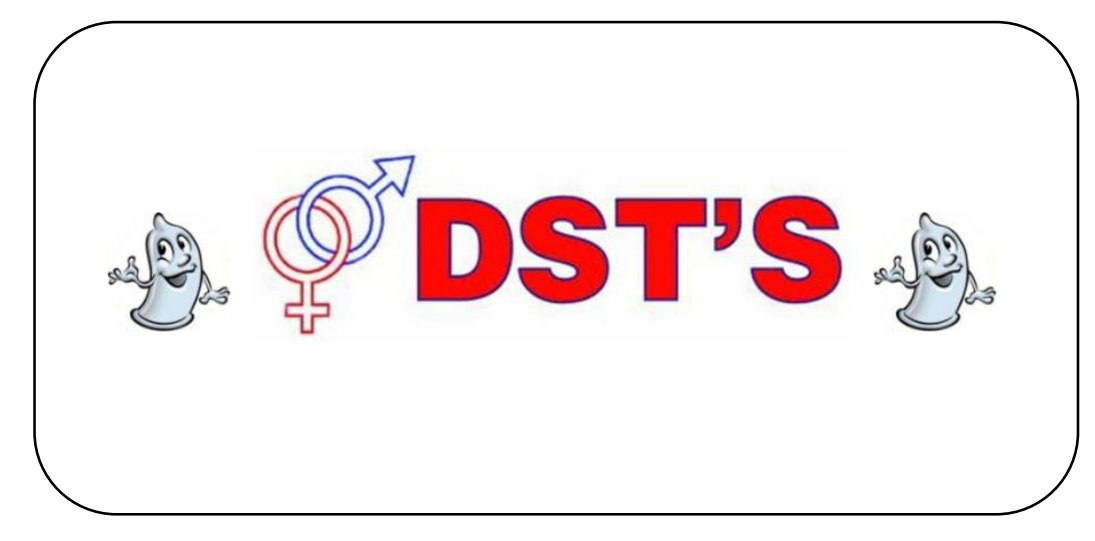




\section{JOGO DIDÁTICO "BOLICHE DAS DST's"}

Este jogo foi desenvolvido no âmbito do projeto PIBID, subprojeto Ciências-Pádua. Trata-se de uma ferramenta didáticopedagógica que visa contribuir com o processo de ensino e aprendizagem do ensino de Ciências do Ensino Fundamental Regular.

\section{Objetivos:}

Abordar o problema do aumento de casos de Doenças Sexualmente Transmissíveis observado a cada ano, entre adolescentes, tornando as discussões mais didáticas e melhorando o processo de construção do conhecimento.

\section{Este jogo contém:}

- 10 pinos de boliche (cada um com uma carta-caso a ser solucionado);

- 1 bola;

- 1 dado de seis faces.

\section{Quantidade de participantes:}

- Máximo de 10 equipes (com 1 representante cada);

- 1 mediador (professor).

\section{Como jogar:}

- O professor deve dividir a turma em no máximo dez equipes (com um representante cada) e definir a ordem das equipes com o lançamento do dado, o jogador que tirar o maior número começa e segue-se a ordem decrescente;

- O representante do primeiro grupo jogará a bola de boliche para derrubar um dos pinos presentes na pista, pegará o pino caído e levará o mesmo para o seu grupo;

- O segundo representante seguirá o mesmo procedimento até que cada grupo possua um pino;

- Quando cada grupo tiver o seu pino, o cronômetro é acionado. Os grupos terão 20 minutos para analisar o paciente apresentado na carta-caso, diagnosticá-lo, esclarecê-lo quanto ao seu quadro sintomático e fazer as devidas recomendações sobre tratamento e profilaxia, escrevendo todas as informações em uma folha de papel;

- Neste tempo, para que o mediador não se torne mero coadjuvante da atividade e possa auxiliar na construção do conhecimento, é de grande importância que percorra os grupos e os auxilie esclarecendo pequenas dúvidas.

- Findado o tempo, o mediador interrompe as atividades dos grupos, e solicita aos representantes de cada grupo (mesma ordem do início da atividade) que apresentem seus pacientes, fale sobre seus diagnósticos e as recomendações indicadas pelo grupo.

- Durante essa apresentação pode haver interações dos demais grupos quanto ao diagnóstico dos pacientes, tornando a construção do conhecimento mais coletiva. 